\title{
Salt effects on the picosecond dynamics of lysozyme hydration water investigated by terahertz time-domain spectroscopy and an insight into the Hofmeister series for protein stability and solubility ${ }^{\dagger}$
}

\author{
Katsuyoshi Aoki,$f^{a}$ Kentaro Shiraki ${ }^{b}$ and Toshiaki Hattori $* a$
}

\begin{abstract}
The addition of salts into protein aqueous solutions causes changes in protein solubility and stability, whose ability is known to be ordered in the Hofmeister series. We investigated the effects of Hofmeister salts on the picosecond dynamics of water around a lysozyme molecule using terahertz time-domain spectroscopy. The change in the absorption coefficient for $200 \mathrm{mg} \mathrm{mL}^{-1}$ lysozyme aqueous solution by the addition of salts was found to depend on the salts used, whereas that for pure water was almost independent of salts. From the difference in the salt concentration dependence for various salts, it has been found that chaotropic anions make the dynamics of water around the lysozyme molecule slower, whereas kosmotropic anions
\end{abstract}

${ }^{a}$ Institute of Applied Physics, University of Tsukuba, 1-1-1 Tennodai, Tsukuba, Ibaraki 305-8573, Japan. E-mail: hattori@bk.tsukuba.ac.jp

${ }^{b}$ Faculty of Pure and Applied Sciences, University of Tsukuba, 1-1-1 Tennodai, Tsukuba, Ibaraki 305-8573, Japan.

$\dagger$ Electronic supplementary information (ESI) available: Lysozyme structure characterization using Fourier transform infrared spectroscopy, lysozyme concentration dependence of the absorption coefficient of the lysozyme aqueous solution, and enlarged plots showing the absorption coefficient of lysozyme-salt mixed aqueous solutions in Fig. 3. See DOI: 10.1039/c5cp06324h

‡ Present address: Lehrstuhl für Physikalische Chemie II, Ruhr-Universität Bochum, 44801 Bochum, Germany. 
make the dynamics faster. The ability of an anion to slow down the water dynamics was found to have the following order: $\mathrm{SCN}^{-}>\mathrm{Cl}^{-}>\mathrm{H}_{2} \mathrm{PO}_{4}^{-}>\mathrm{NO}_{3}{ }^{-} \approx$ $\mathrm{SO}_{4}{ }^{2-}$. This result indicates that the effects of anions on the dynamics of water around the lysozyme molecule are the opposite of those for bulk water. This finding agrees with a prediction from a molecular model proposed by Collins [K. D. Collins, Methods, 2004, 34, 300]. The results presented here are compared with the results from preferential interaction studies and the results from sum frequency generation spectroscopy. These discussions have led to the conclusion that the picosecond dynamics of protein hydration water strongly contributes to protein stability, whereas electrostatic interactions between protein molecules contribute to protein solubility.

\section{Introduction}

Salts change the solubility and stability of proteins in an aqueous solution. ${ }^{1,2}$ The ability of salts to precipitate proteins was reported by F. Hofmeister in $1888 .^{3,4}$ The order of these salts in terms of their ability to precipitate proteins is known as the Hofmeister series. Ions that increase precipitation are called kosmotropes and ions that increase protein solubility are called chaotropes. It is known that not only the solubility but also the stability follows the Hofmeister series. So far, the Hofmeister effects for both solubility and stability have been discussed in relation to a common factor, for example, surface tension. ${ }^{5,6}$ Kosmotropic anions are known to increase surface tension at the surface of the protein, and thus minimize the surface area of the protein. Minimizing the surface area results in protein aggregation and stabilization of the protein structure. Chaotropic anions, on the other hand, decrease surface tension and enlarge the surface area of the protein. The large surface area results in solubilization and destabilization of the protein.

However, the Hofmeister series of anions differs for solubility and stability. The Hofmeister series for the protein solubility depends on the $\mathrm{pH}$ of the aqueous solution of the protein and the isoelectric point $(\mathrm{pI})$ of that protein (Fig. 1). ${ }^{7,8}$ When $\mathrm{pH}>\mathrm{pI}$, 


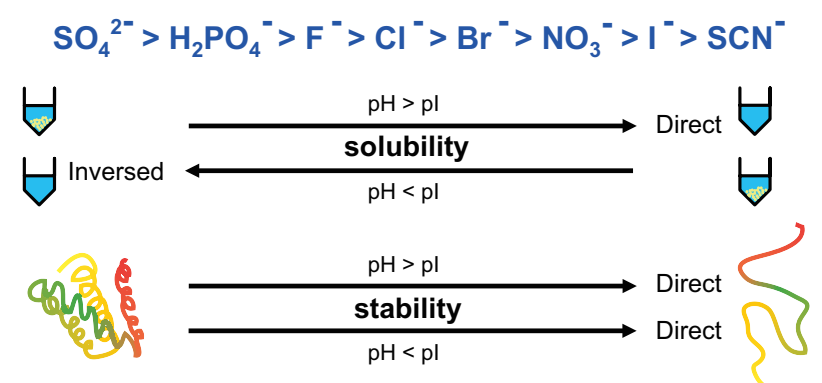

Figure 1. Hofmeister series for protein solubility and stability.

the solubility follows the direct Hofmeister series, whereas the solubility follows the inversed Hofmeister series when $\mathrm{pH}<\mathrm{pI}$. The mechanism of the reversal of the Hofmeister series is explained by adsorption of anions onto the protein surface. ${ }^{9-12}$ On the other hand, the Hofmeister series for the protein stability is independent of the relationship between the $\mathrm{pH}$ and the $\mathrm{pI}$ (Fig. 1). ${ }^{13-16}$ The trend for the stability follows the direct Hofmeister series, regardless of the $\mathrm{pH}$ and the pI. For example, changes in the thermal stability of hen egg white lysozyme and ribonuclease A by specific salts are reported to follow the direct Hofmeister series even under conditions where $\mathrm{pH}<\mathrm{pI} .{ }^{13-15}$ Since the pI of lysozyme and ribonuclease $\mathrm{A}$ is 11.35 and 9.63, respectively, the $\mathrm{pH}$ of the solution is smaller than the pI under usual solution conditions. Sedlák et al. ${ }^{16}$ reported that the changes in the thermal stability of both negatively charged apoflavodoxin (under $\mathrm{pH}>$ pI conditions) and positively charged cytochrome c (under $\mathrm{pH}<\mathrm{pI}$ conditions) follow the direct Hofmeister series. Water around a protein molecule, i.e., hydration water, plays a key role in protein folding and function. The dynamics of hydration water is considered to be an important factor that determines protein stability and protein folding. It is expected that revealing the difference in the mechanism for the solubility and stability change can provide a deeper understanding of protein behavior in aqueous solutions.

Protein hydration has been investigated using various techniques such as NMR, ${ }^{17-21} \mathrm{X}$ ray scattering, ${ }^{22}$ and neutron scattering. ${ }^{22}$ These techniques can reveal water dynamics at a timescale longer than $1 \mathrm{~ns} .{ }^{23}$ Dielectric spectroscopy has also been used to study protein 
hydration. ${ }^{24-29}$ This technique reveals water dynamics in a sub-nanosecond timescale. ${ }^{23}$ However, rearrangement of water molecules, and the making and breaking of hydrogen bonds in water occur at the picosecond timescale. ${ }^{23}$ Therefore, water dynamics in this timescale has an important influence on the physical and chemical properties of proteins. Recently, various spectroscopic techniques such as $2 \mathrm{D}-\mathrm{IR},{ }^{30}$ fs-fluorescence spectroscopy, ${ }^{31,32}$ ultrafast optical Kerr effect spectroscopy, ${ }^{33}$ and terahertz spectroscopy ${ }^{34-42}$ have also been used for studying protein hydration. These techniques can probe water dynamics in the picosecond and subpicosecond timescales and have shown that the dynamics of water around a protein molecule slows down compared to that of bulk water. 2D-IR and fs-fluorescence spectroscopy can probe water molecules surrounding probe atomic groups. ${ }^{23}$ Terahertz spectroscopy can directly probe hydration water in a long-range dynamical hydration shell. ${ }^{43}$ To access the water dynamics at the picosecond timescale directly, terahertz time-domain spectroscopy (THz-TDS) is one of the useful techniques. ${ }^{23}$

So far, the majority of these reports focus on the interactions between protein molecules and water molecules except a few reports using $2 \mathrm{D}-\mathrm{IR}^{30}$ and fs-fluorescence spectroscopy, ${ }^{31}$ which studied the effects of glycerol and guanidine hydrochloride on protein hydration, respectively. To understand the changes in the solubility and the stability, the effects of salt on protein hydration should be revealed. So far, the effects of salt on protein hydration water have been investigated by densimetry, ${ }^{5}$ and a combination method of NMR and difference scanning calorimetry (DSC). ${ }^{44}$ These techniques reveal the dynamics of protein hydration water in the microsecond or longer timescale. Arakawa and Timasheff $^{5}$ discussed the change in protein solubility at $\mathrm{pH}>\mathrm{pI}$ from their results obtained by densimetry, although they examined the salt effects on protein hydration under both conditions of $\mathrm{pH}>\mathrm{pI}$ and $\mathrm{pH}<\mathrm{pI}$. Collins ${ }^{6}$ suggested a microscopic hydration model to consider salt effects on protein hydration. This model predicts that kosmotropic anions make protein hydration weaker, whereas chaotropic anions make it stronger. Collins considered the change in solubility and stability under the $\mathrm{pH}>\mathrm{pI}$ conditions. 
Previously, we investigated the effect of ammonium sulfate on lysozyme hydration water using THz-TDS. ${ }^{45}$ Hen egg white lysozyme (14307 Da, pI = 11.35) was used as a model protein. In this report, effects of specific salts on protein hydration were investigated under the conditions of $\mathrm{pH}<\mathrm{pI}$, using THz-TDS. This study shows that the contribution of anions to water molecules around a lysozyme molecule is the opposite to the contribution of anions to bulk water. In Section 4.1, it is shown that this result agrees with the results from Collins' hydration model. In Section 4, we discuss the relationship among three aspects of hydration water: the water dynamics, preferential binding of water, and the water orientation at the protein surface. The water dynamics is a property of hydration water revealed by THz-TDS, whereas the preferential binding of water is a property of hydration water revealed by densimetry. ${ }^{5}$ In Section 4.2 , these two properties apparently disagree with each other, but are shown to be consistent with each other; preferential binding of water corresponds to faster water dynamics, and that preferential exclusion of water corresponds to slower water dynamics. In Section 4.3, it is shown that the water orientation, which is revealed by sum frequency generation (SFG) spectroscopy, ${ }^{11}$ does not correspond to the water dynamics and preferential adsorption of water. In addition, we propose a hypothesis to explain the differences in the Hofmeister series between protein solubility and protein stability: (i) electrostatic interactions between protein molecules, which arise from anion adsorption on the protein surface, are a major factor that contributes to the protein solubility rather than the protein stability (Section 4.3), (ii) the dynamics of the water molecules, the number of hydrogen bonds, surface tension, and preferential adsorption of water at the protein surface are related to each other, and all strongly contribute to the protein stability rather than the protein solubility (Sections 4.1 and 4.2). 


\section{Experiment}

Hen egg white lysozyme (L6876, Sigma-Aldrich, USA) was used as a model protein, which has a large pI value (11.35). Ammonium sulfate $\left(\left(\mathrm{NH}_{4}\right)_{2} \mathrm{SO}_{4} ; 019-03435\right.$, Wako, Japan), ammonium dihydrogen phosphate $\left(\mathrm{NH}_{4} \mathrm{H}_{2} \mathrm{PO}_{4} ; 012-03305\right.$, Wako, Japan), ammonium chloride $\left(\mathrm{NH}_{4} \mathrm{Cl} ; 017-02995\right.$, Wako, Japan), ammonium nitrate $\left(\mathrm{NH}_{4} \mathrm{NO}_{3} ; 015-03231\right.$, Wako, Japan), and ammonium thiocyanate $\left(\mathrm{NH}_{4} \mathrm{SCN}\right.$; 015-03535, Wako, Japan) were all used as salts. Ammonium perchlorate was tried to be investigated. However, the salt is not suitable for the experiment, because the perchlorate ions precipitated lysozyme during measurements. The lysozyme and salts were used without further purification and were respectively dissolved in pure water (Milli-Q) to prepare stock aqueous solutions. The concentration of the lysozyme stock solution was $267 \mathrm{mg} \mathrm{mL}^{-1}$, which was determined by the absorbance at $280 \mathrm{~nm}$ using a UV-vis spectrophotometer (ND-1000, NanoDrop Technologies, Inc., Wilmington, Del, USA). The lysozyme stock solution of $267 \mathrm{mg} \mathrm{mL}{ }^{-1}$ and the salt aqueous solution of various concentrations were mixed at a volume ratio of 3:1. Thus, the lysozyme-salt (LS) mixed aqueous solutions were prepared. The final concentration of lysozyme in the mixed aqueous solution was $200 \mathrm{mg} \mathrm{mL}^{-1}\left(14 \mathrm{mmol} \mathrm{L}^{-1}\right)$. The high lysozyme concentration makes it easy to detect the change in the absorption coefficient with sufficient accuracy. Below $200 \mathrm{mg} \mathrm{mL} \mathrm{mL}^{-1}$ (corresponding to a volume fraction of 0.14 ), lysozyme molecules are reported to exist as a monomer or a dimer, whereas lysozyme molecules form dynamic clusters, rather than permanent clusters or aggregates, above $200 \mathrm{mg} \mathrm{mL}^{-1}{ }^{46}$ although the report investigated lysozyme in HEPES buffer. In addition, we confirmed that lysozyme aggregation or crystallization does not occur in a day after measurement. From these facts, it is expected that the lysozyme molecules will be well dispersed in the sample solutions. To avoid the effects of buffers on the lysozyme hydration, the $\mathrm{pH}$ of the sample solutions was not adjusted. In addition, buffer can affect the ion adsorption on the lysozyme surface, ${ }^{47}$ which may change the THz-TDS absorption spectra. To determine the amount of salt solution contained in the 
LS solutions, the densities of the solutions were measured using a density meter (DMA 35, Anton Paar, Austria).

Denaturation or aggregation of lysozyme may affect terahertz absorption of water around a lysozyme molecule. To confirm that denaturation and aggregation of lysozyme does not occur in the sample solution, absorbance of the LS mixed solutions at the amide I band (1600-1700 $\mathrm{cm}^{-1}$ ) was measured using a Fourier transform infrared (FT-IR) spectrometer (FT/IR-4200, JASCO, Japan) with a ZnSe attenuated total reflection (ATR) prism (ATR PRO 450-S PKS-ZNSE, JASCO, Japan). Although circular dichroism (CD) spectra in a far UV region are used to evaluate the secondary structure of proteins, we could not carry out CD measurements because of the large absorption of high concentration lysozyme in the sample solution. In addition, $\mathrm{SCN}^{-}$exhibited a large absorption in a wavelength region shorter than $230 \mathrm{~nm}$ (data not shown). This also made it difficult to carry out CD measurements. Fig. S1 (ESI $\dagger$ ) indicates the FT-IR spectra of lysozyme in the LS solutions in the amide I and II regions. The peak position and profile of the lysozyme absorbance spectra were unchanged by the addition of salt. This result indicates that denaturation of lysozyme does not occur in the LS solutions.

The absorption coefficient spectra of the sample solutions were measured using a THzTDS setup and a sample cell that were previously reported by the authors. ${ }^{45}$ To avoid the effects of water vapor in the air, the path of the terahertz waves was purged with nitrogen gas and the relative humidity was reduced. All the measurements were carried out at a temperature of $19.5 \pm 1.0{ }^{\circ} \mathrm{C}$ and a relative humidity of $<5.0 \%$. The thickness of the sample solutions was $0.100 \mathrm{~mm}$. The sample and the reference cell were automatically switched and waveforms of the terahertz fields transmitted through those cells were measured ten times alternatively. From the obtained waveforms, the refractive index, $n$, and the absorption coefficient, $\alpha$, of the sample solutions were obtained as previously reported. ${ }^{45}$ 


\section{Results}

\subsection{Example of observed spectra}

Fig. 2 shows the absorption coefficient and the refractive index spectra of water, $\mathrm{NH}_{4} \mathrm{Cl}$ aqueous solution, lysozyme aqueous solution, and lysozyme- $\mathrm{NH}_{4} \mathrm{Cl}$ mixed aqueous solution. All the measured spectra have no characteristic peak. The absorption coefficients of the lysozyme aqueous solution were smaller than that of pure water. This is caused by two effects: exclusion of water by the lysozyme molecules, and slowing down of the dynamics of water around the lysozyme. ${ }^{43,48-50}$ In the measured frequency region, the addition of $\mathrm{NH}_{4} \mathrm{Cl}$ into pure water and the lysozyme aqueous solution results in a larger absorption coefficient. The increases of the absorption coefficients were almost the same in the measured frequency region. We previously reported changes in the absorption coefficients by the addition of $\left(\mathrm{NH}_{4}\right)_{2} \mathrm{SO}_{4} \cdot{ }^{45}$ The increase in absorption for the lysozyme aqueous solution is twice as large as that for pure water. This difference between the addition of $\left(\mathrm{NH}_{4}\right)_{2} \mathrm{SO}_{4}$ and $\mathrm{NH}_{4} \mathrm{Cl}$ is attributed to different changes in the water dynamics around the lysozyme caused by these salts, which is described below. It should be noted that dynamics changes of water roughly at $1.0 \mathrm{~nm}$ from the lysozyme at the current lysozyme concentration were observed (see ESI, $\dagger$ and Fig. S2).

\subsection{Difference absorption spectra}

To see differences in the absorption change between pure water and the lysozyme solution by the addition of specific salts, the salt concentration dependence of the absorption coefficient of pure water and the lysozyme solution was measured (Fig. 3). The measured concentration range for each salt was up to the concentration where lysozyme precipitation occurs, $C_{\max }$, which is shown in Table 1 . The order of the concentration roughly agrees with the inversed Hofmeister series. For the salt aqueous solutions, the absorption coefficients increased linearly as a function of the salt concentration. On the other hand, 

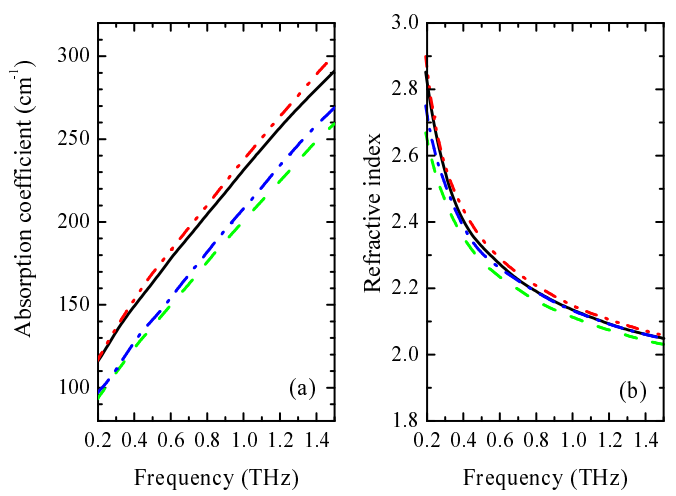

Figure 2. Spectra of (a) absorption coefficients and of (b) refractive indices. Black solid line: pure water, red dashed two dotted line: $0.25 \mathrm{~mol} \mathrm{~L}^{-1} \mathrm{NH}_{4} \mathrm{Cl}$ aqueous solution, green dashed line: $200 \mathrm{mg} \mathrm{mL}^{-1}$ lysozyme aqueous solution, blue dashed dotted line: lysozyme $\left(200 \mathrm{mg} \mathrm{mL} \mathrm{m}^{-1}\right)-\mathrm{NH}_{4} \mathrm{Cl}\left(0.25 \mathrm{~mol} \mathrm{~L}{ }^{-1}\right)$ mixed aqueous solution.

Table 1. Maximum salt concentrations, $C_{\max }$, at which protein precipitation and crystallization do not occur in the $200 \mathrm{mg} \mathrm{mL}^{-1}$ lysozyme aqueous solution $\left(20^{\circ} \mathrm{C}\right)$.

\begin{tabular}{cc}
\hline Salt & $C_{\max }(\mathrm{mol} \mathrm{L}-1)$ \\
\hline$\left(\mathrm{NH}_{4}\right)_{2} \mathrm{SO}_{4}$ & 0.375 \\
$\mathrm{NH}_{4} \mathrm{H}_{2} \mathrm{PO}_{4}$ & 0.625 \\
$\mathrm{NH}_{4} \mathrm{Cl}$ & 0.25 \\
$\mathrm{NH}_{4} \mathrm{NO}_{3}$ & 0.15 \\
$\mathrm{NH}_{4} \mathrm{SCN}$ & 0.06
\end{tabular}


nonlinear changes of the absorption coefficient can be seen, especially in the lysozyme$\mathrm{NH}_{4} \mathrm{H}_{2} \mathrm{PO}_{4}$ mixed aqueous solution. Although we evaluated the error of the absorption coefficient as $1 \mathrm{~cm}^{-1}$ at $1 \mathrm{THz}$, further data are required to judge whether nonlinearity exists or not, because the difference spectra reported by Vinh et al. ${ }^{48}$ could not be reproduced well unless fitting parameters obtained by a linear function shown below were used. Therefore, the absorption coefficient changes of both of water and the lysozyme solution were fitted by linear functions as follows:

$$
\alpha_{\mathrm{S}}\left(C_{\mathrm{S}}, \omega\right)=b_{\mathrm{S} 1}(\omega)+b_{\mathrm{S} 2}(\omega) C_{\mathrm{S}}
$$

for water, and

$$
\alpha_{\mathrm{LS}}\left(C_{\mathrm{S}}, \omega\right)=b_{\mathrm{LS} 1}(\omega)+b_{\mathrm{LS} 2}(\omega) C_{\mathrm{S}}
$$

for the lysozyme solution, where $\alpha_{\mathrm{S}}$ is the absorption coefficient of the salt aqueous solutions, $\alpha_{\mathrm{LS}}$ is the absorption coefficient of the LS aqueous solutions, and $C_{\mathrm{S}}$ is the salt concentration in these aqueous solutions. The unit of $C_{\mathrm{S}}$ is $\mathrm{mol} \mathrm{L}^{-1}$. In these equations, $b_{\mathrm{S} 1}, b_{\mathrm{S} 2}, b_{\mathrm{LS} 1}$, and $b_{\mathrm{LS} 2}$ are parameters obtained using the least squares fitting method. The errors of these parameters were also calculated. The slopes of the fitted lines for pure water were found to be almost independent of salts except in the case of $\mathrm{NH}_{4} \mathrm{H}_{2} \mathrm{PO}_{4}$. The small slope for the $\mathrm{NH}_{4} \mathrm{H}_{2} \mathrm{PO}_{4}$ aqueous solution is attributed to the protons that compose $\mathrm{NH}_{4} \mathrm{H}_{2} \mathrm{PO}_{4}$, because only $\mathrm{NH}_{4} \mathrm{H}_{2} \mathrm{PO}_{4}$ has protons in the salts that we used. In contrast to the salt aqueous solutions, the slopes for the lysozyme solutions depend on the salt species. Although changes in $\mathrm{pH}$ caused by the addition of salt may affect the change in the absorption coefficient of the LS solutions, a correlation between the changes in the $\mathrm{pH}$ and the absorption coefficient was found to be small (data not shown). The slope differences between pure water and the lysozyme solution are attributed to changes in the dynamics of water around the lysozyme caused by the addition of salts, ${ }^{45}$ because the conformation of the lysozyme was not changed by the salts as described in the experimental section. 

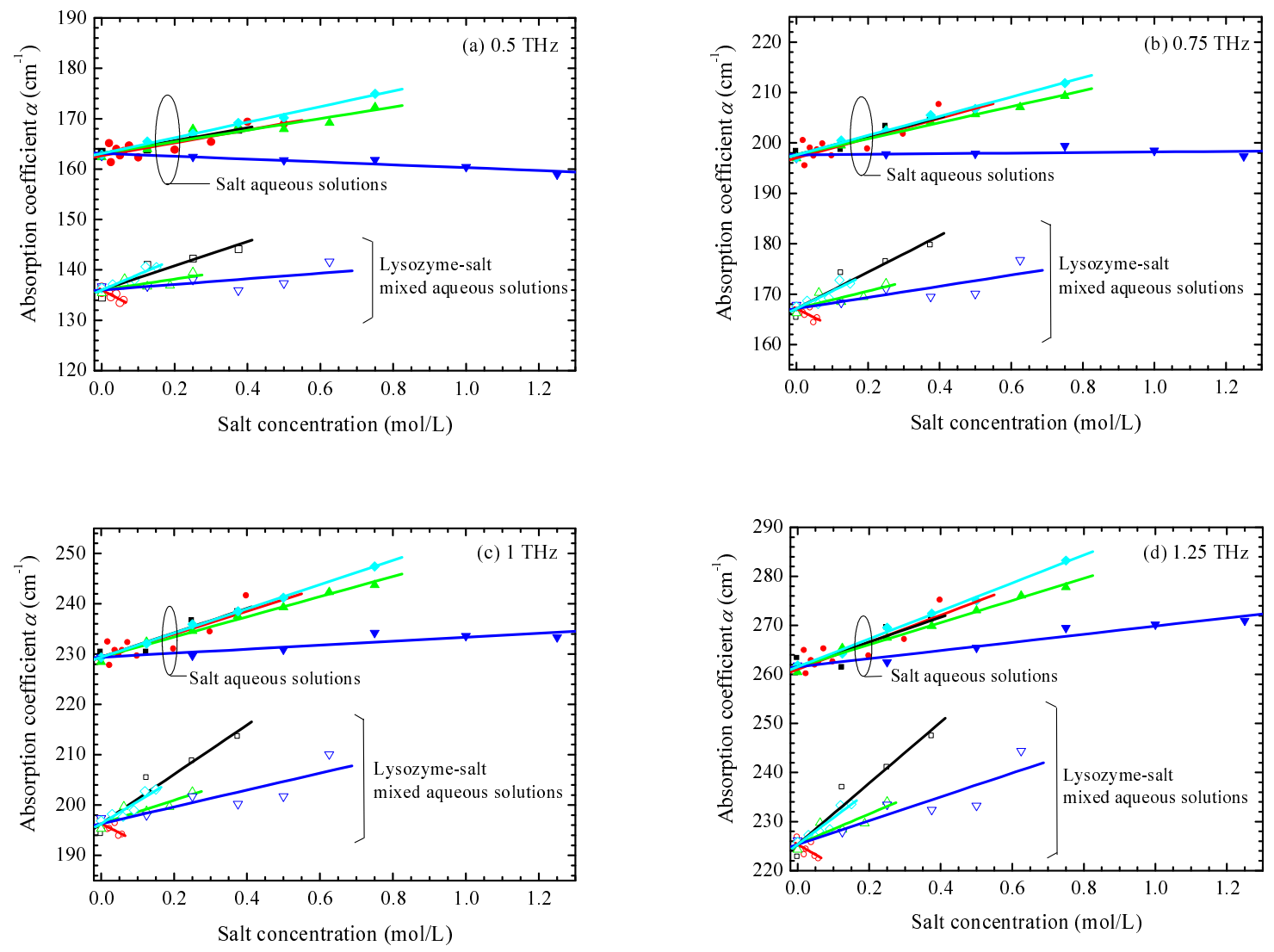

Figure 3. Salt concentration dependence of the salt aqueous solutions (closed plots) and the lysozyme (200 mg mL $\mathrm{mL}^{-1}$ )-salt mixed aqueous solutions (open plots) at (a) $0.5 \mathrm{THz}$, (b) $0.75 \mathrm{THz},\left(\right.$ c) $1.0 \mathrm{THz}$, and (d) $1.25 \mathrm{THz}$. $\left(\mathrm{NH}_{4}\right)_{2} \mathrm{SO}_{4}$ : black square, $\mathrm{NH}_{4} \mathrm{H}_{2} \mathrm{PO}_{4}$ : blue inverted triangle, $\mathrm{NH}_{4} \mathrm{Cl}$ : green triangle, $\mathrm{NH}_{4} \mathrm{NO}_{3}$ : light blue rhombus, $\mathrm{NH}_{4} \mathrm{SCN}$ : red circle. The enlarged plots of the lysozyme-salt mixed solutions are shown in the ESI, $\dagger$ (Fig. S3-S6). 
To extract the change in the absorption coefficient of water around the lysozyme, the absorption coefficient of the LS mixed solution, $\alpha_{\mathrm{LS}}$, was subtracted by that of the salt solution, $\alpha_{\mathrm{S}}$, using the following equation at each frequency: ${ }^{45}$

$$
\Delta \alpha\left(C_{\mathrm{S}}, \omega\right)=\alpha_{\mathrm{LS}}\left(C_{\mathrm{S}}, \omega\right)-\frac{\rho_{\mathrm{LS}}\left(C_{\mathrm{S}}\right)-c_{\mathrm{L}}}{\rho_{\mathrm{S}}\left(C_{\mathrm{S}}\right)} \alpha_{\mathrm{S}}\left(C_{\mathrm{S}}, \omega\right)
$$

where $\rho_{\mathrm{S}}$ is the density of the salt solution, $\rho_{\mathrm{LS}}$ is the density of the LS mixed solution, and $c_{\mathrm{L}}$ is the lysozyme concentration in the LS solution. The unit of $c_{\mathrm{L}}$ is $\mathrm{g} \mathrm{mL}^{-1}$. By the factor multiplied by $\alpha_{\mathrm{S}}$, the exclusion of water (or salt solution) by lysozyme is taken into account.

The difference spectra of $\Delta \alpha$ thus obtained are shown in Fig. 4. In this calculation of $\Delta \alpha$, we used $\alpha_{\mathrm{S}}$ and $\alpha_{\mathrm{LS}}$ obtained by the fitting as expressed in eqn (1) and (2). Previously, we reported the hydration number of a lysozyme molecule (the number of water molecules in the dynamical hydration shell) and its change by the addition of $\left(\mathrm{NH}_{4}\right)_{2} \mathrm{SO}_{4},{ }^{45}$ where the hydration number was calculated from $\Delta \alpha$ at the frequency where $\Delta \alpha$ takes the minimum value. However, in the present study, the hydration numbers could not be obtained with sufficient accuracy for the lysozyme- $\mathrm{NH}_{4} \mathrm{SCN}$ and the lysozyme- $\mathrm{NH}_{4} \mathrm{Cl}$ solutions. Even in these cases, we can find the rate of change of the hydration number by the addition of salt at each frequency as shown in the following section.

\subsection{Changes in the absorption of water around lysozyme per 1 M salt}

To find the rate of hydration number change, we calculated changes in $\Delta \alpha$ for the unit salt concentration. By substituting eqn (1) and (2) for eqn (3), the following equation can be obtained:

$$
\Delta \alpha\left(C_{\mathrm{S}}, \omega\right)=\left\{b_{\mathrm{LS} 1}(\omega)-\frac{\rho_{\mathrm{LS}}\left(C_{\mathrm{S}}\right)-c_{\mathrm{L}}}{\rho_{\mathrm{S}}\left(C_{\mathrm{S}}\right)} b_{\mathrm{S} 1}(\omega)\right\}+\left\{b_{\mathrm{LS} 2}(\omega)-\frac{\rho_{\mathrm{LS}}\left(C_{\mathrm{S}}\right)-c_{\mathrm{L}}}{\rho_{\mathrm{S}}\left(C_{\mathrm{S}}\right)} b_{\mathrm{S} 2}(\omega)\right\} C_{\mathrm{S}}
$$




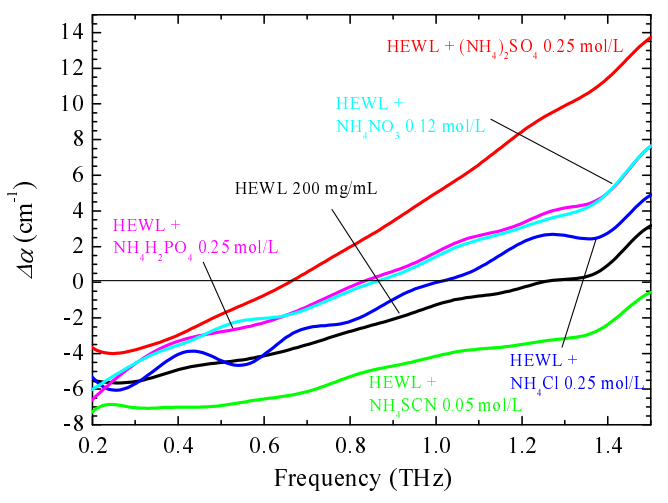

Figure 4. Difference absorption spectra of lysozyme $\left(200 \mathrm{mg} \mathrm{mL}^{-1}\right)$-salt mixed solutions subtracted by those of salt aqueous solutions using eqn (3). Black: without salts, red: $\left(\mathrm{NH}_{4}\right)_{2} \mathrm{SO}_{4} 0.25 \mathrm{~mol} \mathrm{~L}-1$, pink: $\mathrm{NH}_{4} \mathrm{H}_{2} \mathrm{PO}_{4} 0.25 \mathrm{~mol} \mathrm{~L}-1$, blue: $\mathrm{NH}_{4} \mathrm{Cl} 0.25 \mathrm{~mol} \mathrm{~L}-1$, light blue: $\mathrm{NH}_{4} \mathrm{NO}_{3} 0.12 \mathrm{~mol} \mathrm{~L}{ }^{-1}$, green: $\mathrm{NH}_{4} \mathrm{SCN} 0.05 \mathrm{~mol} \mathrm{~L}{ }^{-1}$.

In this equation, the factor multiplied to $C_{\mathrm{S}}$ indicates the rate of change of the absorption coefficient by the addition of salt, which is described as

$$
A_{2}(\omega)=\left\{b_{\mathrm{LS} 2}(\omega)-\frac{\rho_{\mathrm{LS}}\left(C_{\mathrm{S}}\right)-c_{\mathrm{L}}}{\rho_{\mathrm{S}}\left(C_{\mathrm{S}}\right)} b_{\mathrm{S} 2}(\omega)\right\} .
$$

Although the factor $\frac{\rho_{\mathrm{LS}}\left(C_{\mathrm{S}}\right)-c_{\mathrm{L}}}{\rho_{\mathrm{S}}\left(C_{\mathrm{S}}\right)}$ is a function of $C_{\mathrm{S}}$, the variance was small $(<1 \%)$ and can therefore be ignored. Thus, we regarded the factor as a constant and included the variance in the error of $A_{2}$. To calculate the error of $A_{2}$, the errors of $b_{\mathrm{LS} 2}$ and $b_{\mathrm{S} 2}$, which were obtained by least squares fitting in Fig. 3, were used. The spectra of $A_{2}$ obtained are shown in Fig. 5(a). The error of $A_{2}$ was large especially in the lysozyme- $\mathrm{NH}_{4} \mathrm{SCN}$ mixed solution because the concentration range that we could investigate was small. Based on no conformational change within the experimental conditions, as described above, we can expect that the absorption coefficient of the lysozyme does not change by the addition of salt. Therefore, we can attribute the obtained $A_{2}$, i.e., changes in $\Delta \alpha$ dependent on $C_{\mathrm{S}}$, to changes in the absorption of water around the lysozyme molecule. According to the results from molecular dynamics simulation, ${ }^{43}$ the water molecules at the protein surface 
have slower dynamics and the terahertz absorption by the water is smaller compared with that of bulk water below $2 \mathrm{THz}$. If the water dynamics at the protein surface becomes slightly faster by the addition of salt, terahertz absorption of water can be expected to become larger, because the properties of the water tend to become slightly closer to that of bulk water. On the other hand, if the water dynamics at the protein surface becomes slightly slower, the absorption can be expected to become smaller. The hydration number change per salt concentration, $a_{\mathrm{N} 2}$, is obtained by dividing the $A_{2}(\omega)$ by the absorption coefficient of water as follows:

$$
a_{\mathrm{N} 2}(\omega)=-\frac{A_{2}(\omega)}{b_{\mathrm{S} 1}(\omega)} \rho_{\mathrm{W}} \frac{1}{M_{\mathrm{W}}} \frac{1}{C_{\mathrm{L}}}
$$

where $\rho_{\mathrm{W}}$ is the density of water, $M_{\mathrm{W}}(=18 \mathrm{Da})$ is the molecular weight of the water molecule, and $C_{\mathrm{L}}\left(=14.0 \mathrm{mmol} \mathrm{L}{ }^{-1}\right)$ is the molar concentration of lysozyme. The obtained spectra of $a_{\mathrm{N} 2}$ are shown in Fig. 5(b). Note that $a_{\mathrm{N} 2}$ is not the actual number of water molecules in the lysozyme hydration shell but the absorption change of water around the lysozyme molecule normalized by the absorption of bulk water. A positive $a_{\mathrm{N} 2}$ value indicates faster dynamics of the water around the lysozyme molecule compared to that in the absence of the salt, whereas a negative $a_{\mathrm{N} 2}$ value indicates slower dynamics.

We find that the order of ability of the salts to make the water dynamics around the lysozyme molecule slower is

$$
\mathrm{SCN}^{-}>\mathrm{Cl}^{-}>\mathrm{H}_{2} \mathrm{PO}_{4}^{-}>\mathrm{NO}_{3}^{-} \approx \mathrm{SO}_{4}^{2-}
$$

This order agrees with the Hofmeister series with the exception of $\mathrm{NO}_{3}^{-}$. This result indicates that the presence of kosmotropic anions makes the water dynamics around the lysozyme molecule faster and that the presence of chaotropic anions makes it slower. The obtained $a_{\mathrm{N} 2}$ depends on frequency. The large absolute value of $a_{\mathrm{N} 2}$ in the higher frequency region indicates that the absorption change of water around the lysozyme molecule is relatively large compared to the absorption of bulk water. The salt effects on the dynamics 

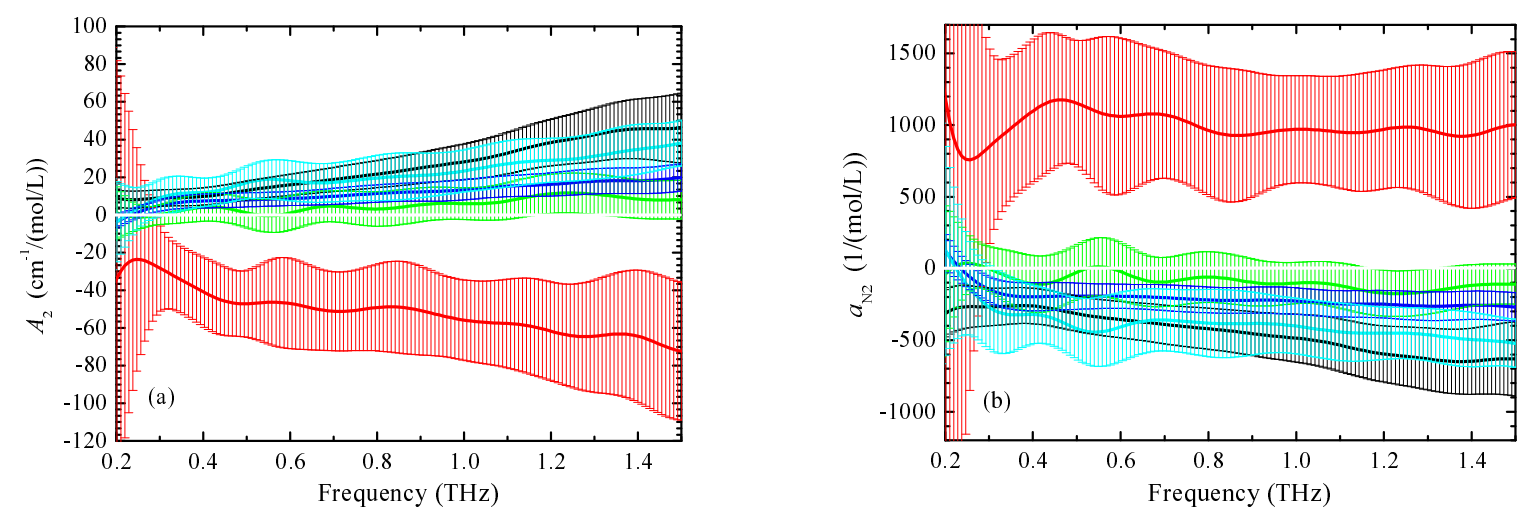

Figure 5. (a) Changes in the absorption coefficient by the addition of salts at each frequency. (b) Changes in the hydration number of lysozyme by the addition of salts calculated at each frequency. Black: $\left(\mathrm{NH}_{4}\right)_{2} \mathrm{SO}_{4}$, blue: $\mathrm{NH}_{4} \mathrm{H}_{2} \mathrm{PO}_{4}$, green: $\mathrm{NH}_{4} \mathrm{Cl}$, light blue: $\mathrm{NH}_{4} \mathrm{NO}_{3}$, red: $\mathrm{NH}_{4} \mathrm{SCN}$. Belts around the solid lines indicate error bars. Large error bars, especially in $\mathrm{NH}_{4} \mathrm{SCN}$, result from the narrow salt concentration range examined. 
of the water around the lysozyme molecule are the opposite of the effects seen on bulk water dynamics, which will be discussed in the next section.

The results obtained here shows that $\mathrm{NO}_{3}^{-}$is rather categorized as a kosmotropic anion. So far, $\mathrm{NO}_{3}^{-}$has been considered as a chaotropic anion. This deviation is attributed to the high lysozyme concentration. The deviation of $\mathrm{H}_{2} \mathrm{PO}_{4}^{-}$in the Hofmeister series observed for the solubility (Table 1) can also be attributed to the high lysozyme concentration. For better understanding of the deviation, further investigation of protein hydration at high concentration is required.

\section{Discussion}

\subsection{Comparison with Collins' hydration model}

The present study using terahertz spectroscopy has revealed that kosmotropic anions make the dynamics of the water around the lysozyme molecule faster, whereas chaotropic anions make it slower. In contrast, for bulk water, kosmotropic anions strengthen the water structure, which corresponds to slower water dynamics. Chaotropic anions weaken the water structure, which corresponds to faster water dynamics. This opposite effect of anions on hydration water and bulk water has been predicted by Collins. ${ }^{6}$

In Collins' model, Collins considered how anions affect the hydrogen bonding of water molecules in the vicinity of a protein molecule under the conditions of $\mathrm{pH}>\mathrm{pI}$. Kosmotropic anions generally strengthen the structure of bulk water, which makes the interactions between protein hydration water and the anion stronger, and which makes the interactions between the protein and the hydration water weaker. Thus, kosmotropic anions make the solvent poorer. In the poorer solvent, the surface area of the protein exposed to the solvent becomes smaller, leading to reduced protein solubility and higher stability of the protein. On the other hand, chaotropic anions weaken the structure of bulk water. The weak interaction between water and the anion strengthens the inter- 
action between the protein and its hydration water. Thus, chaotropic anions make the solvent better. In the better solvent, the exposed surface area of the protein becomes larger, leading to higher protein solubility and lower protein stability.

How do kosmotropic and chaotropic anions affect the protein hydration water when $\mathrm{pH}<\mathrm{pI}$ ? In this model, the interaction between the protein and its hydration water depends only on the interaction between water and the anion, and is independent of the surface charge of the protein, which corresponds to the relationship between the $\mathrm{pH}$ and the pI. Therefore, the protein hydration is expected to be independent of the relationship between the $\mathrm{pH}$ and the $\mathrm{pI}$; kosmotropic anions make the interaction between the protein and its hydration water weaker, whereas chaotropic anions make this interaction stronger. This is consistent with the fact that protein stability is independent of the relationship between the $\mathrm{pH}$ and the $\mathrm{pI}$, but is inconsistent with the fact that the protein solubility depends on the relationship. The $\mathrm{pH}$ dependence of the change in protein solubility is rather consistent with the results from SFG spectroscopy. ${ }^{11}$

In Collins' model, the effects of anions on the number of hydrogen bonds in the hydration shell are discussed. Since the number of hydrogen bonds is expected to be directly related to the dynamics of water, a decrease in the number of hydrogen bonds should result in faster dynamics of water and larger terahertz absorption. Therefore, the prediction that kosmotropic anions reduce the number of hydrogen bonds in the vicinity of a protein is expected to lead to an increase in the terahertz absorption of water at the protein surface under the influence of kosmotropes. The increase of hydrogen bonds in water, on the other hand, should result in slower dynamics of water and a decrease in the terahertz absorption of water. Our results show that kosmotropic anions increase the absorption of water around the lysozyme, whereas chaotropic anions decrease it under the conditions of $\mathrm{pH}<\mathrm{pI}$. This result agrees with Collins' model expanded to the case of $\mathrm{pH}$ $<$ pI. It is reasonable to expect that the dynamics of water around the protein molecule observed by THz-TDS does not change even when $\mathrm{pH}>\mathrm{pI}$. 


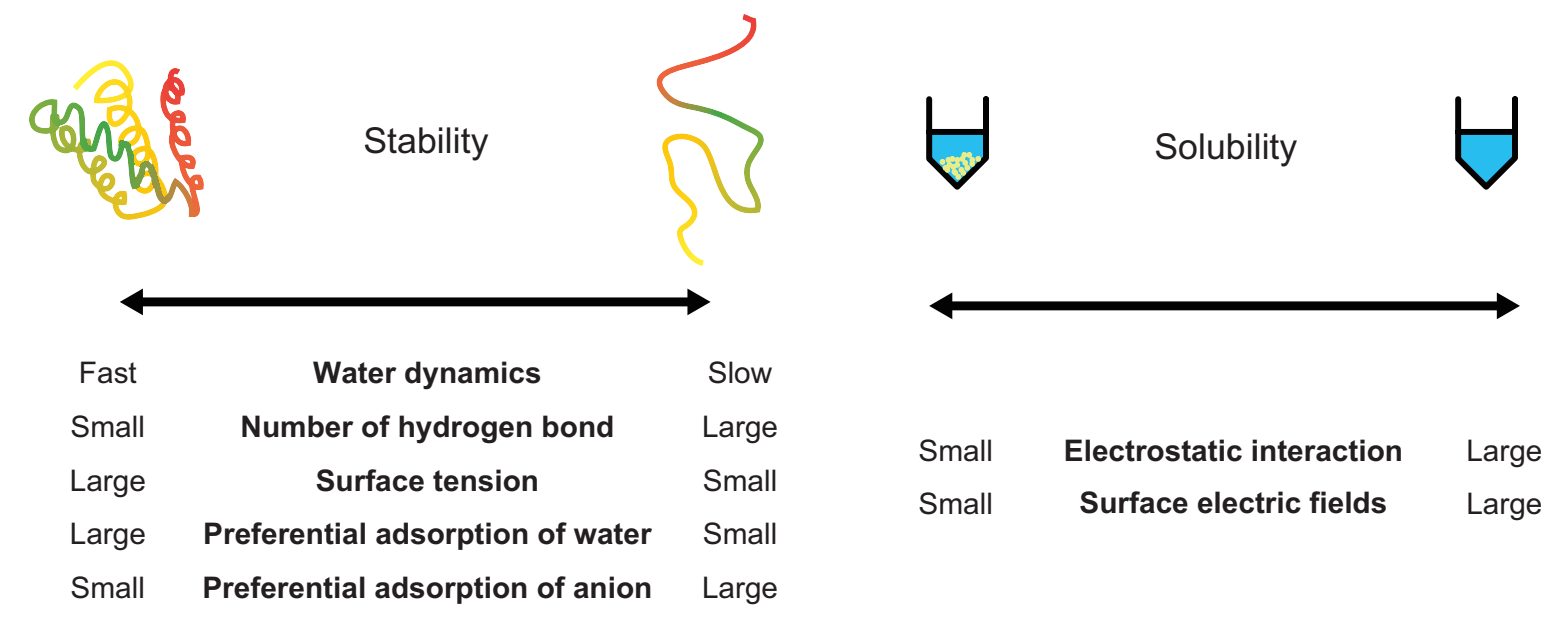

Figure 6. Quantities relating to changes in the protein stability and protein solubility by anions.

Here, the relationship of the dynamics of water in the hydration shell with protein stability and its solubility is discussed. Collins' model, which mentions the case of $\mathrm{pH}>$ pI, can explain the changes in protein stability and solubility caused by the addition of salts. When this model is expanded to the case of $\mathrm{pH}<\mathrm{pI}$, the model can explain the change in protein stability, because the anion effects on the number of hydrogen bonds are independent of the relation between the $\mathrm{pH}$ and the $\mathrm{pI}$. Therefore, it is concluded that the number of hydrogen bonds and the dynamics of water around the protein molecule strongly contribute to protein stability regardless of the $\mathrm{pH}$ and the $\mathrm{pI}$ (Fig. 6). It is also stated that the picosecond dynamics of water in the hydration shell is a key factor that determines the protein structure and its function. On the other hand, under the conditions of $\mathrm{pH}<\mathrm{pI}$, results from the model disagree with the change in protein solubility because the Hofmeister series for the protein solubility is inversed by the inversion of the $\mathrm{pH}$ and the pI. The change in protein solubility is consistent with the results from SFG spectroscopy, ${ }^{11}$ as described below. 


\subsection{Preferential interaction}

The effects of salt on protein hydration have also been investigated using densimetry and preferential interaction theory. ${ }^{51}$ This method can reveal the amount of preferentially bound anions and water molecules on the protein surface. In general, additives such as kosmotropes, osmolytes, and sugars, which stabilize and precipitate proteins, are preferentially excluded from the protein surface, whereas additives such as chaotropes, urea, and guanidine hydrochloride, which destabilize proteins and increase their solubility, are

preferentially bound on the surface. ${ }^{5,52-59}$ Arakawa and Timasheff reported the amount of anions and water molecules bound on the protein surface under $\mathrm{pH}<\mathrm{pI}$ (lysozyme) and $\mathrm{pH}>\mathrm{pI}$ (BSA: bovine serum albumin) conditions. ${ }^{5}$ According to the report, the amounts of bound anions and water are independent of the relation between the $\mathrm{pH}$ and the $\mathrm{pI} ; \mathrm{SO}_{4}{ }^{2-}$ is strongly excluded from both lysozyme and BSA surfaces when compared with $\mathrm{Cl}^{-}$. This fact indicates that kosmotropic anions are preferentially excluded from the protein surface regardless of the $\mathrm{pH}$ and the $\mathrm{pI}$, leading to preferential binding of water on the surface, whereas chaotropic anions are preferentially bound on the surface, leading to preferential exclusion of water. The fact that chaotropic anions are bound on the protein surface more preferentially agrees with the results from molecular dynamics $(\mathrm{MD})^{60}$ simulation and SFG spectroscopy. ${ }^{11}$

In their analysis, exclusion of kosmotropic anions results in an increase in surface tension, which leads to a smaller surface area of the protein being exposed to the solvent. To minimize the area exposed, proteins tend to fold and aggregate. Thus, the protein is stabilized, and its solubility decreases under the influence of kosmotropic anions. Binding of chaotropic anions, on the other hand, results in a decrease in surface tension, leading to a larger surface area. The change in surface tension caused by the addition of salts is consistent with the results from MD simulation. ${ }^{61}$ To maximize the surface area exposed, proteins tend to unfold and attempt not to aggregate. Then, the protein is destabilized and its solubility increases. This scenario is for the case of $\mathrm{pH}>\mathrm{pI}$, although they also 
investigated the case of $\mathrm{pH}<\mathrm{pI}$ and their results on the surface tension were independent of the relationship between the $\mathrm{pH}$ and the $\mathrm{pI}$. In the case of $\mathrm{pH}>\mathrm{pI}$, this understanding can explain the changes in the solubility and the stability by the addition of salt. Also in the case of $\mathrm{pH}<\mathrm{pI}$, the surface tension change agrees with the change in the protein stability, although it cannot explain the change in solubility. Therefore, the change in surface tension, as well as the changes in the number of hydrogen bonds and the dynamics of water in the protein hydration shell, all strongly contributes to the stability of the protein. Furthermore, we can expect that the water dynamics at the protein surface becomes faster when the surface tension increases by the addition of salt, and that the water dynamics becomes slower when the surface tension decreases (Fig. 6).

Their experiment also revealed the preferential binding and exclusion of water at the protein surface, which are quantities complementary to the preferential binding and exclusion of salts. Therefore, the preferential exclusion and binding of water can also be related to the protein stability. Kosmotropic anions increase the amount of preferentially bound water on the protein, which one may tend to regard as characteristics of stronger protein hydration. Our experiment, however, showed that kosmotropic anions make the dynamics of water around the protein faster, which corresponds to weaker protein hydration. Chaotropic anions, in contrast, decrease the amount of preferentially bound water, which one may tend to regard as characteristics of weaker protein hydration. However, our results show that chaotropic anions make the dynamics of water around the protein slower, which corresponds to stronger protein hydration. This apparent disagreement between the preferential binding/exclusion and the dynamics is due to the difference in the nature of the experimental methods. Densimetry reveals the amount of the static bound water on the protein surface, whereas THz-TDS reveals the water dynamics at the picosecond timescale. Nevertheless, both quantities are independent of the relationship between the $\mathrm{pH}$ and the $\mathrm{pI}$, which corresponds to the fact that the Hofmeister series for the protein stability is independent of the relationship between the $\mathrm{pH}$ and the pI. Our 
analysis described above suggests that preferential binding of water should correspond to faster water dynamics, and that preferential exclusion of water should correspond to slower water dynamics (Fig. 6). This fact indicates that kosmotropic anions increase the water around the protein because of the preferential exclusion of the anion and decrease the dynamical hydration water, whereas chaotropic anions decrease the water around the protein because of the preferential adsorption of the anion and increase the dynamical hydration water.

Arginine improves the solubility and suppresses the aggregation of biomolecules, ${ }^{62}$ which makes arginine one of the useful additives in the pharmaceutical industry. ${ }^{63}$ Arakawa et al. mentioned that the stabilizing effects of arginine are attributed to the increase in the large surface tension for bulk water ${ }^{52}$ which is consistent with our results.

\subsection{Sum frequency generation spectroscopy}

Flores et al. ${ }^{11}$ reported the effects of salt on the strength of water orientation at the model surface using SFG spectroscopy to reveal the mechanism of the solubility change. Using the information obtained on the strength of water orientation, they discussed the distribution of ions at the interface. When $\mathrm{pH}>\mathrm{pI}$, kosmotropic anions make the orientation strength weaker, which results from less anion adsorption on the model surface, whereas chaotropic anions preserve the orientation strength, which results from anion adsorption. The lower anion adsorption results in weak electric fields at the protein surface, leading to weaker electrostatic interaction between protein molecules. Thus, the protein molecules can get closer to each other in the presence of kosmotropic anions, which results in protein aggregation. When $\mathrm{pH}<\mathrm{pI}$, kosmotropic anions maintain the orientation strength, which results from a lower anion adsorption, whereas chaotropic anions make the orientation strength weaker, which results from anion adsorption. Thus, the distance between the protein molecules can become small in the presence of chaotropic anions, which results in protein aggregation. This analysis successfully explains the decrease of the pro- 
tein solubility in the presence of chaotropic anions and the increase of it by kosmotropic anions under $\mathrm{pH}<\mathrm{pI}$. They concluded that adsorption of anions, which influences the electrostatic interaction among proteins, contributes to the protein solubility.

Here, we discuss the protein stability with respect to the electrostatic interaction. Stronger orientation of water molecules due to the stronger electric field may be regarded, in a sense, as a state of stronger hydration of the protein, whereas weak orientation may be related to weaker hydration of the protein. When $\mathrm{pH}>\mathrm{pI}$, kosmotropic anions make the orientation strength weaker, which may be regarded as a state of weaker protein hydration. On the other hand, chaotropic anions preserve the orientation strength, which may be regarded as stronger hydration of the protein. When $\mathrm{pH}<\mathrm{pI}$, the effects of anions on the orientation strength are reversed. This fact shows that the effects of anions on the stability of proteins cannot be explained in terms of the state of hydration related to the water molecule orientation because the Hofmeister series for the stability does not depend on the relationship between the $\mathrm{pH}$ and the $\mathrm{pI}$. The strength of water orientation revealed by SFG spectroscopy does not correspond to the water dynamics that was revealed by terahertz spectroscopy and explained by Collins' model, nor the surface tension and the preferential binding/exclusion of water revealed by densimetry. The strength of water orientation, which indicates electric fields at the protein surface, contributes not to the protein stability but to the protein solubility (Fig. 6). Electrostatic interactions between protein molecules, which arise from anion adsorption on the protein surface, is regarded as a major factor that contributes to the protein solubility (Fig. 6).

Nihonyanagi et al. ${ }^{12}$ reported the effects of cations on water orientation strength at the negatively charged interface and the effects of anions on the strength at the positively charged interface. Their results showed that the anion effects on the strength follow the Hofmeister series, whereas the cation effects do not. They concluded that Hofmeister effects by anions could be explained by ion adsorption and that the effects by cations arise from a change in hydrogen bonding strength. This means that the dominant factor of the 
Hofmeister effect differs in the cases of anions and cations. Our results and discussions suggest that the dominant factor of the solubility and stability changes also differs. Various aspects of hydration and different techniques should be applied for further studies of the Hofmeister effects. Although we proposed a hypothesis here that the dynamics of water and the strength of water orientation have different contributions, in many cases a large degree of orientation is considered to correspond to binding and the slower dynamics of water molecules. For example, kosmotropic ions, especially in salt aqueous solutions without biomacromolecules, make the water structure strong, which can be regarded as the slower water dynamics and stronger water orientation. From our experimentation and discussion, the orientation strength and dynamics of hydration water should not be recognized as being equivalent to one another.

\section{Conclusion}

We investigated the effects of salts on the dynamics of water around a lysozyme molecule using terahertz time-domain spectroscopy. We found that changes in the absorption coefficient of the lysozyme aqueous solution by the addition of salt depend on the salts used, whereas changes in the absorption coefficient of water are almost independent of the salts. We calculated the change in the absorption coefficient of water around a lysozyme molecule and the hydration number change by the addition of salt, from which changes in the dynamics of water around the lysozyme molecule were discussed. The order of the ability of anions to make the water dynamics around the lysozyme molecule slower is: $\mathrm{SCN}^{-}>\mathrm{Cl}^{-}>\mathrm{H}_{2} \mathrm{PO}_{4}^{-}>\mathrm{NO}_{3}^{-} \approx \mathrm{SO}_{4}{ }^{2-}$. Kosmotropic anions, such as sulfate ions, make the dynamics of water around the lysozyme faster, whereas chaotropic anions, such as thiocyanate ions, make the dynamics slower. On the other hand, it is well accepted that kosmotropic anions make the dynamics of bulk water slower, whereas chaotropic anions make the dynamics faster. This opposite contribution of anions is explained by 
Collins' hydration model. The dynamics of water around a protein molecule, the surface tension of the solvent, and preferential binding/exclusion of water, which are independent of the relationship between the $\mathrm{pH}$ of the solution and the $\mathrm{pI}$ of the protein, are concluded to contribute to the protein stability strongly and explains the fact that the Hofmeister series for the protein stability is not inversed. The electrostatic interaction between protein molecules, which depends on the relationship between the $\mathrm{pH}$ and the $\mathrm{pI}$, strongly contributes to the protein solubility. In addition, the orientation strength revealed by sum frequency generation spectroscopy and the dynamics of hydration water revealed by terahertz spectroscopy should not be recognized as being equivalent to one another.

\section{Acknowledgements}

The authors wish to thank Prof. Hideaki Kano, Dr Hiromichi Hoshina, Prof. Muneaki Hase, and Prof. Taka-aki Ishibashi for their useful discussions.

\section{References}

1 Y. Zhang and P. S. Cremer, Curr. Opin. Chem. Biol., 2006, 10, 658-663.

2 K. D. Collins and M. W. Washabaugh, Q. Rev. Biophys., 1985, 18, 323-422.

3 F. Hofmeister, Arch. Exp. Pathol. Pharmakol., 1888, 24, 247-260.

4 W. Kunz, J. Henle and B. W. Ninham, Curr. Opin. Colloid Interface Sci., 2004, 9, $19-37$.

5 T. Arakawa and S. N. Timasheff, Biochemistry, 1984, 23, 5912-5923.

6 K. D. Collins, Methods, 2004, 34, 300-311.

7 M. M. Ries-Kautt and A. F. Ducruix, J. Biol. Chem., 1989, 264, 745-748. 
8 K. Aoki and J. Hori, Arch. Biochem. Biophys., 1962, 97, 75-79.

9 M. Boström, D. F. Parsons, A. Salis, B. W. Ninham and M. Monduzzi, Langmuir, 2011, 27, 9504-9511.

10 A. Salis, F. Cugia, D. F. Parsons, B. W. Ninham and M. Monduzzi, Phys. Chem. Chem. Phys., 2012, 14, 4343-4346.

11 S. C. Flores, J. Kherb and P. S. Cremer, J. Phys. Chem. C, 2012, 116, 14408-14413.

12 S. Nihonyanagi, S. Yamaguchi and T. Tahara, J. Am. Chem. Soc., 2014, 136, 61556158.

13 J. W. Bye and R. J. Falconer, Protein Sci., 2013, 22, 1563-1570.

14 C. H. Ramos and R. L. Baldwin, Protein Sci., 2002, 11, 1771-1778.

15 P. H. von Hippel and K.-Y. Wong, J. Biol. Chem., 1965, 240, 3909-3923.

16 E. Sedlák, L. Stagg and P. Wittung-Stafshede, Arch. Biochem. Biophys., 2008, 479, $69-73$.

17 G. Otting and K. Wuethrich, J. Am. Chem. Soc., 1989, 111, 1871-1875.

18 G. Otting, E. Liepinsh and K. Wuthrich, Science, 1991, 254, 974-980.

19 V. P. Denisov and B. Halle, J. Mol. Biol., 1995, 245, 682-697.

20 B. Halle, T. Andersson, S. Forsen, B. Lindman and B. Lindman, J. Am. Chem. Soc., 1981, 103, 500-508.

21 S. H. Koenig, K. Hallenga and M. Shporer, Proc. Natl. Acad. Sci. U.S.A., 1975, 72, 2667-2671.

22 D. I. Svergun, S. Richard, M. H. J. Koch, Z. Sayers, S. Kuprin and G. Zaccai, Proc. Natl. Acad. Sci. U.S.A., 1998, 95, 2267-2272. 
23 U. Heugen, G. Schwaab, E. Bründermann, M. Heyden, X. Yu, D. M. Leitner and M. Havenith, Proc. Natl. Acad. Sci. U.S.A., 2006, 103, 12301-12306.

24 K. Yokoyama, T. Kamei, H. Minami and M. Suzuki, J. Phys. Chem. B, 2001, 105, $12622-12627$.

25 C. Cametti, S. Marchetti, C. Gambi and G. Onori, J. Phys. Chem. B, 2011, 115, $7144-7153$.

26 B. E. Pennock and H. P. Schwan, J. Phys. Chem., 1969, 73, 2600-2610.

27 M. Suzuki, J. Shigematsu and T. Kodama, J. Phys. Chem., 1996, 100, 7279-7282.

28 A. Oleinikova, P. Sasisanker and H. Weingärtner, J. Phys. Chem. B, 2004, 108, 84678474.

29 E. Dachwitz, F. Parak and M. Stockhausen, Ber. Bunsen-Ges. Phys. Chem, 1989, 93, $1454-1458$.

30 J. T. King and K. J. Kubarych, J. Am. Chem. Soc., 2012, 134, 18705-18712.

31 J. Peon, S. K. Pal and A. H. Zewail, Proc. Natl. Acad. Sci. U.S.A., 2002, 99, 1096410969.

32 S. K. Pal, J. Peon and A. H. Zewail, Proc. Natl. Acad. Sci. U.S.A., 2002, 99, 17631768.

33 K. Mazur, I. A. Heisler and S. R. Meech, J. Phys. Chem. A, 2012, 116, 2678-2685.

34 J. Xu, K. W. Plaxco and S. J. Allen, Protein Sci., 2006, 15, 1175-1181.

35 J. Xu, K. W. Plaxco and S. J. Allen, J. Phys. Chem. B, 2006, 110, 24255-24269.

36 J. W. Bye, S. Meliga, D. Ferachou, G. Cinque, J. A. Zeitler and R. J. Falconer, J. Phys. Chem. A, 2014, 118, 83-88. 
37 S. Ebbinghaus, S. J. Kim, M. Heyden, X. Yu, U. Heugen, M. Gruebele, D. M. Leitner and M. Havenith, Proc. Natl. Acad. Sci. U.S.A., 2007, 104, 20749-20752.

38 S. Ebbinghaus, S. J. Kim, M. Heyden, X. Yu, M. Gruebele, D. M. Leitner and M. Havenith, J. Am. Chem. Soc., 2008, 130, 2374-2375.

39 B. Born, S. J. Kim, S. Ebbinghaus, M. Gruebele and M. Havenith, Faraday Discuss., 2009, 141, 161-173.

40 K. Meister, S. Ebbinghaus, Y. Xu, J. G. Duman, A. DeVries, M. Gruebele, D. M. Leitner and M. Havenith, Proc. Natl. Acad. Sci. U.S.A., 2013, 110, 1617-1622.

41 S. Ebbinghaus, K. Meister, B. Born, A. L. DeVries, M. Gruebele and M. Havenith, J. Am. Chem. Soc., 2010, 132, 12210-12211.

42 H. Vondracek, J. Dielmann-Gessner, W. Lubitz, M. Knipp and M. Havenith, J. Chem. Phys., 2014, 141, 22D534.

43 M. Heyden and M. Havenith, Methods, 2010, 52, 74-83.

44 K. Tompa, P. Bánki, M. Bokor, P. Kamasa, G. Lasanda and P. Tompa, Biophys. J., 2009, 96, 2789-2798.

45 K. Aoki, K. Shiraki and T. Hattori, Appl. Phys. Lett., 2013, 103, 173704.

46 L. Porcar, P. Falus, W.-R. Chen, A. Faraone, E. Fratini, K. Hong, P. Baglioni and Y. Liu, J. Phys. Chem. Lett., 2010, 1, 126-129.

47 F. Cugia, M. Monduzzi, B. W. Ninham and A. Salis, RSC Adv., 2013, 3, 5882-5888.

48 N. Q. Vinh, S. J. Allen and K. W. Plaxco, J. Am. Chem. Soc., 2011, 133, 8942-8947.

49 F. Sterpone, G. Stirnemann and D. Laage, J. Am. Chem. Soc., 2012, 134, 4116-4119.

50 M. Marchi, F. Sterpone and M. Ceccarelli, J. Am. Chem. Soc., 2002, 124, 6787-6791. 
51 J. C. Lee, K. Gekko and S. N. Timasheff, Methods Enzymol., 1979, 61, 26-49.

52 T. Arakawa, D. Ejima, K. Tsumoto, N. Obeyama, Y. Tanaka, Y. Kita and S. N. Timasheff, Biophys. Chem., 2007, 127, 1-8.

53 T. Arakawa and Y. Kita, Curr. Protein Pept. Sci., 2014, 15, 608-620.

54 T. Arakawa and S. N. Timasheff, Biochemistry, 1982, 21, 6545-6552.

55 T. Arakawa and S. N. Timasheff, Biophys. J., 1985, 47, 411-414.

56 T. Arakawa and S. N. Timasheff, Biochemistry, 1982, 21, 6536-6544.

57 J. C. Lee and S. N. Timasheff, J. Biol. Chem., 1981, 256, 7193-7201.

58 T. Arakawa and S. N. Timasheff, Biochemistry, 1984, 23, 5924-5929.

59 V. Prakash, C. Loucheux, S. Scheufele, M. J. Gorbunoff and S. N. Timasheff, Arch. Biochem. Biophys., 1981, 210, 455-464.

60 J. Paterová, K. B. Rembert, J. Heyda, Y. Kurra, H. I. Okur, W. R. Liu, C. Hilty, P. S. Cremer and P. Jungwirth, J. Phys. Chem. B, 2013, 117, 8150-8158.

61 F. Bogár, F. Bartha, Z. Násztor, L. Fábián, B. Leitgeb and A. Dér, J. Phys. Chem. $B, 2014, \mathbf{1 1 8}, 8496-8504$.

62 K. Shiraki, M. Kudou, S. Fujiwara, T. Imanaka and M. Takagi, J. Biochem., 2002, 132, 591-595.

63 H. Hamada, T. Arakawa and K. Shiraki, Curr. Pharm. Biotechnol., 2009, 10, 400-407. 